\title{
CHRONOSOMES AND QUANTITATIVE STRATIGRAPHY
}

\author{
Cedric M. Griffiths ${ }^{* 1}$ and Ulf Nordlund ${ }^{* 2}$ \\ *1 BP Research, BP/Sutoil Alliance, Ranheimsveien 10, N - 7004 Trondheim, Norway \\ *2 Institute for Petroleum Technology and Applied Geophysics, University of Trondheim, N - \\ 7034 Trondheim, Norway
}

\begin{abstract}
The three - dimensional mapping of time - bounded bodies of rock (chronosomes, after Schultz, 1982) forms the basis of quantitative prediction of both rock properties and bios tratigraphy in the subsurface.

High resolution seismic data can provide mappable reflection - bounded units (RBU's) with a vertical resolution of 10 to $20 \mathrm{~ms}$ two - way - time (approximately $10-20 \mathrm{~m}$ in Tertiary sediments). Lateral resolution varies from $10 \mathrm{~m}$ in a 3D survey, to $500 \mathrm{~m}$ plus in the case of a regional $2 \mathrm{D}$ survey. We can begin with the working hypothesis that seismic reflectors are isochrons and map RBU's to chronosomes. Each chronosome has a unique combination of ge ological time interval and paleogeographical location. They are composed, generally, of lesser chronosomes below the current observational resolution, and can be combined to form higher - order chronosomes. The chronosome concept is therefore both time, and scale independent. Seismic stratigraphy forms a genetic framework in which the vertical development of chrono somes at any given location can be related to regional and/or global processes. Current seis mic stratigraphic concepts and terminologies are essentially two-dimensional, yet sediment distribution throughout a basin is, of course, three - dimensional. Only by mapping chrono some development in three-dimensions can one find the predictive relationships between shape, location and content that are needed both for practical application of quantitative stratigraphy and in the theoretical analysis of causative processes within the basin.

Key words : Chronosome, Quantitative stratigraphy, Geological time interval, paleogeogra phy, Biostratigraphy
\end{abstract}

\section{INTRODUCTION}

We will start by defining a few terms and explain ing some of the concepts that will be used in this pa per.

\section{Quantitative Stratigraphy}

The literal meaning of stratigraphy is "descrip tion of layers", and Grabau (1913) defined the term as

"The inorganic side of historical geology or the de velopment through the successive geological ages of the Earth's rocky framework or lithosphere."

Use of the term "stratigraphy" has come to in clude both the organic content of rock layers (bios tratigraphy) and indirect indications of layering (seismic sequence stratigraphy).

Quantitative stratigraphy has been defined in many ways, by many people. The aims of quantitative stratigraphy have been stated as:

- To quantify the definition and correlation of strati graphic units

- To develop, improve, and promote the use of com puter algorithms in stratigraphic definition and correlation

- To promote the formal use and testing of multiple working hypotheses in stratigraphy

- To develop formal geological process models for hypothesis testing

In general we can say that Quantitative Stratigra phy aims to

- Maximize predictive capacity with a minimum of data
In practice it is the combination of:

- stratigraphic principles

- mathematics

- computer science

- statistics

in an interrelated group of methods designed to assist in, and improve confidence in, stratigraphy.

The development of a quantitative predictive ca pacity based on stratigraphic principles is fundamen tal to the research being carried out in many areas under the name of quantitative stratigraphy.

Of the many problems that we look to stratigra phy to solve, one of the most important concerns that of the stratigraphic correlation surface (SCS) at a given moment in geological time. This surface is the diachronous surface across which all superposed stra ta are younger than all underlying strata. It would have been possible to walk (swim) anywhere over this preserved surface at a unique instant in time.

The stratigraphic correlation surface is important because it is the closest we can come to the paleogeo graphical surface, and on that depends our ability to model processes and thence make predictions.

Biostratigraphy has played a major historical role in identifying this surface, and quantitative bios tratigraphy (Gradstein, Agterterg, Brower and Schwarzacher (1985), Agterberg (1990)) is playing an increasingly important role in helping us to under stand the uncertainties involved in different environ mental predictions at different ages.

The stratigraphic correlation surface may be 
identified using techniques such as quantitative bios tratigraphy, chemostratigraphy (Williams, 1988) and magnetostratigraphy (Johnson et al, 1988), but it is also possible to nail the relative position of these sur faces to an absolute time (see Harland et al, 1989, and Gradstein, 1990 for discussions). Radio-isotope stratigraphy has helped to place absolute dates on many lithologies overlying important surfaces, and the combination of isotopic dating, magnetic reversal stratigraphy, and probabilistic biostratigraphy or chemostratigraphy enables absolutely dated strati graphic correlation surfaces to be mapped in many environments to a resolution of better than $1 \mathrm{Ma}$ (at least in the Mesozoic and Cenozoic).

In non - exposed basins the need for SCS maps is even more important, both from a mineral exploita tion and from an academic point of view. However none of the above techniques are of any use without samples or borehole measurements. In this case our understanding of surfaces must be based largely on seismic data. Vail et al. (1977) presented a working hypothesis that seismic reflection were in fact SCS's. Since this time the hypothesis has been tested exten sively but is still not proven beyond doubt. We will as sume in this paper that a seismic reflection (allowing for multiples. migration problems etc.) is a strati graphic correlation surface.

Once the stratigraphic correlation surface has been identified throughout a basin then regional or local variation in the internal properties of the overly ing chronosome are of interest.

\section{The "chronosome"}

Digitizing seismic reflections is equivalent to digi tizing stratigraphic correlation surfaces if (and it is not yet proven) such horizons are indeed time planes as proposed by the "Exxon School". Schultz (1982) has proposed the term "chronosome" for the 3D space bounded by such planes. Schultz recognized the prob lems of equating seismic reflections with time - planes and at the present time we should accept the assump tion as an un - proven working hypothesis. Given the above assumptions, the relationship between chrono somes is therefore the relationship between paleogeo graphic surfaces in 3D. It is not necessary to use seismic sections to derive chronosome maps. The sur faces defined during a "facies architecture" study (Miall, 1985) are also time planes and will define chronosome boundaries. Having defined the chronosome we are faced with the problem of quantifying its character. Some properties are immediately avail able. Volume is defined once a suitable time - depth conversion is available (in the case of seismic data). Shape, surface, and attitude pose problems that are more intractable. Defining and describing the shape of $3 \mathrm{D}$ bodies in a useful way is a problem that has been avoided by the geological community, which has been satisfied with terms such as "wedge - shaped" ," elongate" etc.

There have been many recent developments in $3 \mathrm{D}$ visualization Tipper (1977), Auerbach and Schaeben (1990), Klein et al. (1989), Marschallinger (1991), but such representations do not provide functional descriptions. By a functional description we mean a de scription that can be used directly to make predictions concerning the distribution of lithological properties within the chronosome. Connell and Brady (1985) dis cuss the problem of generalizing functional form de scriptions using a declarative strategy. In a declarative strategy the description is complex and all - inclu sive (at a given resolution) and can be either verbose or mathematical. The shape components may be list ed as in a verbal description using syntactic symbols such as "straight" "long" "curved" etc. linked to op erators such as "connected-to)", "orthogonal-to" etc. The mathematical equivalent of this is the bicubic spline or the use of "Coon" patches as described by Tipper (1977). A formal 3D description of a body may be built up in this way and compared to other tem plates of generalized geological bodies. The represen tation is all-inclusive at the chosen resolution but does not itself indicate functionality. It is a convenient visualization tool that leaves traditional qualitative in terpretation methods unaffected. Tipper has shown how such representations can be manipulated to show the effects of compaction or deformation, and they can of course be used to calculate volumes.

An alternative image analysis strategy is known as "procedural". In this case the body itself is defined using rather simple concepts and data structures but the knowledge concerning these structures is incorpo rated in complex heuristics. This is equivalent to mathematical formalization of the simple geological descriptions "wedge-shaped", "drape" etc. which are simple generalizations which only have contextual meanings.

A good discussion of the functional form problem is to be found in Thorn (1988) Chapter 8. Chorley (Chorley (1957), and Chorley and Morley (1959) in: Thorn (1988) p. 102) developed a functional form based on the "lemniscate" (Fig. 1) described in radial coordinates by
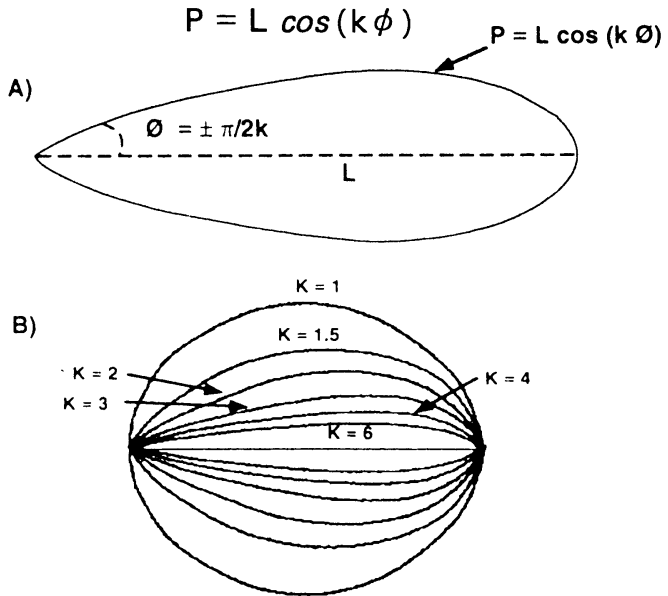

Fig.1. Chorley's lemniscate representation of a drainage system form. 
where $\phi$ lies between $-\pi / 2 \mathrm{k}$ and $+\pi / 2 \mathrm{k}, 1$ is the longest diameter of the loop and $k>-1$ is a constant (when $\mathrm{k}=1$ the loop is a circle). This form description was developed for drainage basins but also has a role in fan form description. A modification of the lemnis cate to describe different fan types is shown in Fig. 2. In Fig. 3 a simple skeletal shape function is developed that can handle one of the major problems of subsur face shape identification. The margins of subsurface bodies are often defined only by a lack of resolution, that is they may continue laterally in all directions be low seismic resolution. The skeletal shape function identifies the salient characteristics that are incontroversially identifiable on seismic i.e. shallowest ob served point, thickest observed point and extension both in maximum gradient direction and perpendicu lar to this.

Combinations of such simple shapes may be use fully applied to well - bounded chronosomes with a di rect relationship to depositional processes, or they could be used to test whether or not a given form is re lated to an unmodified depositional process or has been influenced by erosion. More complex shapes are usual at the limit of seismic resolution because the chronosome usually represents an aggregate of many individual depositional events, the number of which will increase with the subsurface depth of the chronosome. In this case the shape of the chronosome will be more often related to preservation potential than indi vidual depositional processes,

\section{LITHOSOME PREDICTION}

There have been many different approaches to this next step. The traditional qualitative estimates based on paleogeographical models have been supplemented recently by a host of quantitative techniques developed as a response to the needs of hydrocarbon - reservoir description. We will briefly examine below some of the techniques that have been published over the past few years in the field of one, two, and three - dimen sional quantitative lithostratigraphic prediction, and see how they relate to the chronosome.

In current terminology we are largely concerned with predicting the contents of parasequences or parasequence sets (Van Wagoner et al., 1988, p. 39). A parasequence is defined as a "relatively conformable succession of genetically related beds or bed - sets bounded by marine-flooding surfaces". Note however that the concepts of being "relatively conformable" and "genetically related" are not defined.

Walter Schwarzacher in his 1975 book on "Sedimentation models and Quantitative Stratigraphy" and again in Schwarzacher (1985) discussed the prin ciples of predictive lithostratigraphy. Dealing first with one-dimensional sections he extended the models to two dimensions basing the simulations on em pirical observations of lithology occurrence and tran sition.

In its simplest form such a model consists of ran dom occurrences of lithologies. In the one - dimen- sional case this can be represented as

$$
x_{t}=\varepsilon_{t}
$$

where $x_{t}$ is the new state which is a function only of the random number $\varepsilon_{\mathrm{t}}$.

In the case of a palasequence influenced by cyclic events, such as orbital forcing, the model may appear as

$$
\mathbf{x}_{\mathbf{t}}=\mathbf{A} \sin \frac{2 \pi t}{\omega}+\varepsilon_{t}
$$

in which the lithology at $x_{t}$ is a function of a single deterministic cycle of frequency $\omega$ and amplitude A, with an additional random function (Schwarzacher, 1985 , p. 368).

A one-dimensional Milankovitch model would have at least the function

$$
x_{t}=A \cos \frac{2 \pi t}{23 k a}+B \cos \frac{2 \pi t}{41 k a^{\prime}}+C \cos \frac{2 \pi t}{100 k a}+\varepsilon_{t}
$$

where $\mathrm{A}, \mathrm{B}$, and $\mathrm{C}$ are the amplitudes of dominant frequencies of the precision, obliquity and eccentricity cycles respectively. Note that the cycles are assumed to be in phase in this case. A good discussion of the re lationship between the precision, obliquity and eccen tricity (ETP after Imbrie (1985)) cycles and the sed iment record, taking into consideration phase lag is to be found in Imbrie (1985) and Clemens et al. (1991).

Systems that can be considered to have a "memo ry", that is, to be partially dependent on the previous state are called Markov processes after Markov (1924). Such processes can be described by

$$
x_{t}=\mathbf{a} x_{t-1}+\varepsilon_{t}
$$

where $\mathrm{a}$ is a constant less than unity.

Note that the Markov process concept as stated above is empirical in nature, it says nothing about the causative process that leads $x_{t}$ to depend on $x_{t-1}$. the Milankovitch approach however is an attempt to link causative processes to the observed record. In a simi lar vein the global eustatic sea level curve of Haq et al. (1987) attempts to provide a causative model for sed imentation patterns. If we carry out a Fourier spectral analysis of the sea-level changes as recorded by the $\partial^{18} \mathrm{O}$ record from DSDP and ODP legs we obtain spectra that contain slightly modified Milankovitch frequencies for the first $0.4 \mathrm{Ma}$ years or so but then the spectra begin to deviate (Imbrie, 1985). Older than $1 \mathrm{Ma} \mathrm{BP}$ the resolution of dating usually drops below that necessary to identify orbital forcing components. In exceptional cases, where we have a combination of high continuous sedimentation rates, unusually good absolute dating, and where assumptions may be made concerning the differential sedimentation rates between isochrons (Griffiths, B $\phi \mathrm{e}$, and Hodkinson, 1992 ) it may be possible to translate depth to geologi cal time at such high resolution that orbital forcing components may be recognized for at least some of the Neogene. However the uncertainty in dating the large scale changes in relative sea level as recorded by 


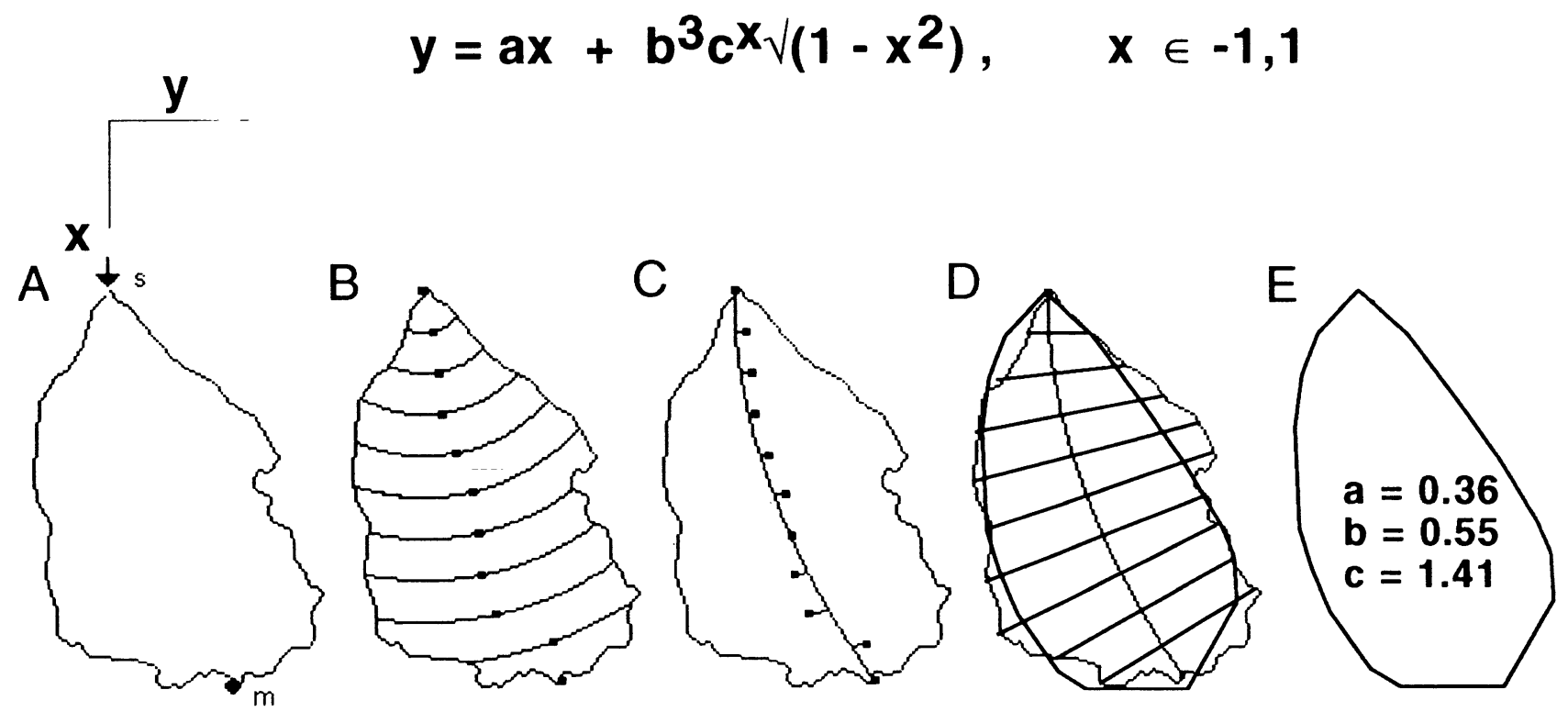

Fig.2. A functional 2D chronosome shape description.

Haq et al. (1987) means that in the Mesozoic the likely error in absolute age exceeds the longest eccentricity period. Since most actual sedimentation events are probably dominated by periodicities less than or equal to Milankovitch cycles (storm, flood, and mon soon frequencies for example) then these longer peri od relative sea level controls are influencing the relationships between chronosome sets or parasequences rather than the internal distribution of lithosomes.

Empirical Markov models may be applied in two and three dimensions (Schwarzacher. 1985, p.404). In the two-dimensional case we can express the relationship as

$$
x_{s, t}=\alpha x_{s-1, t}+\beta x_{s, t-1}+\varepsilon_{s, t}
$$

where $\mathbf{s}$ is the lateral direction and $\mathbf{t}$ is time (vertical). The lithology at $x_{s . t}$ is thus a function of both the un derlying lithology at $x_{s, t-1}$, and the laterally preced ing lithology at $x_{6-1, t}$. Note that in this case $s$ is direc tional and the assumption is that $s$ and $t$ are orthogo nal. If, however the $\mathrm{s}$ direction is both parallel to the direction of sedimentation, and parallel to an unconformity or chronosome lower boundary then the mod el begins to be sedimentologically more realistic. In the three - dimensional case

$$
x_{a, b, t}=\alpha x_{a-1, b, t}+\beta x_{a, b-1, t}+\tau x_{a, b, t-1}+\varepsilon_{a, b, t}
$$

he two spatial coordinates a and $b$ would be related to chronosome boundaries. The scale of the chronosome is now important. If the time period involved is so great that the $x_{t-1}$ to $x_{t}$ relationship crosses a break in sedimentation then we cannot reasonably expect the underlying assumptions to hold, and predictions based on this model will not be successful. Within a parasequence then we can build a lot of our knowledge concerning cyclicity and sedimentary processes into this simple equation by making the constants into time and space-dependent functions and changing the coordinate relationships. Given empirical or theoretical knowledge concerning the cumulative probabilities of transitions between likely lithologies within the chronosome then a Monte Carlo simulation can produce a probabilistic or stochastic model of the lithosome - to - chronosome mapping.

This latter approach to the mapping of lithosomes to the chronosome in two or three dimensions has been well described by Haldorsen and Damsleth (1990), and Damsleth et al. $(1990,1992)$. Damsleth et al.'s $3 \mathrm{D}$ facies units within which the predictive mod elling is to take place are lithosomes such as "mouth bar sands", "calcite", "delta plain fines", rather than chronosomes, but there is no reason why the same approach should not be used at the chronosome level.

Several people have built heuristic models of intra - chronosome variation. The modelling of alluvial systems provides an interesting example. Bridge and Leeder (1979), and Mackey and Bridge (1992) among others, have proposed models of meandering and avulsing river channels set in fine-grained overbank deposits. Their models are not empirical "stochastic" models such as described above, but based on a sim plification of the physical controls on alluvial sedi mentation. Because of the complexity of modelling a hydraulic system over many thousands of years many short-cuts are taken which involve simplification of the physical processes and their scaling in time.

The variables considered include channel-belt dimensions, floodplain width, variation in depositional rate, differential compaction, and tectonic tilt ing. There are no hydraulic parameters input to the model, and the model is not capable of deciding itself whether, or where, to deposit sand given an input grain-size distribution. The modelling concerns the distribution of sand channels treated as bounded, dis crete, plastic bodies set in a fine-grained matrix. This is typical of the type of quantitative model that the present state of mathematics and computing pow 
er enables. The model explicitly includes more under standing of the way river channels behave than a pure ly empirical stochastic model such as those of Jacod and Joathon (1971, 1972). Begg and King (1985), Hal dorsen and Macdonald (1987), but the models are not constrained by chronostratigraphic position or chronosome shape, they exist in a sort of stratigraph ic limbo.

\section{Geostatistics}

Another approach is that of so - called "geostatis tics" (Matheron $(1962,1963))$. The underlying as sumption here is that the variance of a desired proper ty is itself a function of the distance between, and ori entation of observations. In other words the uncer tainty in prediction of a value at a given point in space has a functional relationship to the distance to (and orientation in relation to) measured neighboring points.

There has been an increase in interest in the topic over the past few years (Agterberg and Griffiths. 1991). Using geostatistical techniques in our present case, the successful prediction of properties within the chronosome is based either on the identification of a suitable analog on which the variogram structure can be based, or on measured one - , or two-dimensional data sets from the actual chronosome. In the case of subsurface data, for example from hydrocarbon reservoirs or aquifers, the identification of suitable analogues is not a trivial matter. Often neither the analogues themselves nor the observed facies are defined in such a way as to enable the uncertainty in se lection to be quantified. Vertical lithosome structure within the chronosome is often available from wells drilled through the chronosome but this must be translated to lateral structure to be of practical use. Information from dipmeter and chronosome attitude and orientation are useful in this context.

\section{Fractals}

The use of fractals in lithosome prediction (Hewett (1986) and Hewett and Behrens (1990)) close ly parallels the use of geostatistics, and the same problems arise in practice.

\section{Quantitative Dynamic Stratigraphy}

The use of sediment process modelling (Har baugh (1970)), or quantitative dynamic stratigraphy (QDS) as it has come to be called (Cross (1990)) also has a role to play in lithosome prediction within the chronosome. The two basic factors; preserved chronosome shape (at all scales), and the underlying (depositional) surface, provide the necessary constraints for three-dimensional QDS. If this type of study is carried out at the limit of resolution then the problems of running 3D models over large time inter vals can be avoided, and the results tightly con strained. Quantitative information concerning 3D chronosome orientation in relation to the underlying surface (see Nordlund and Griffiths, this volume) can provide gradient, minimum sedimentation rate, de positional slope and other input parameters for the model.

There are obviously problems with the application of QDS as the chronosome time interval increases. Thus a Jurassic chronosome of $1 \mathrm{Ma}$ duration will be the preserved record of many different sedimentation and erosion processes. Nevertheless we can still gen erate a series of sufficient models each of which meet the constraints of the preserved chronosome. We must also, however have the possibility of an independent test of the range of possible solutions. The may be $u l$ timately provided by stratigraphic inversion.

\section{Seismic Inversion}

Several workers have looked at the link between stratigraphic forward models (in this case within the chronosome) and the seismic record. The potential with this type of analysis is that we can constrain the lithosome model derived using one or several of the above-mentioned techniques within the chronosome by producing a synthetic acoustic (in the case of sub surface seismic), or visual reflectance (in the case of surface outcrop) section that can be compared quanti tatively with the observed section. An acoustic reflectance (seismic) section is a function of reflectance (acoustic impedance contrast) between superimposed layers within the chronosome, whereas the visual light reflectance is a function of mineralogy, porosity and water saturation. In the seismic case therefore it is relatively simple to prepare a forward model but difficult to produce a necessary inverse model (in the sense that many sufficient inverse models can be produced).

A major problem here is that of mapping lithosome properties such as mineralogy, grain - size dis tribution, state of compaction and diagenesis to velocity and density (see papers by Samec et al (1989), Blangy (1992)). This is problematical because the mapping from mineralogy, grain size and sorting, porosity and cementation state, to log - scale petrophysics, let alone to low frequency acoustic reflection, is not straightforward. This problem, that of scaling, has engaged several workers over the past few years and is still not fully resolved.

The integration of forward and inverse modelling would seem to offer the best hope of quantitative litho some prediction in the long term, and the present state-of-the-art is that we can produce forward models of chronosome fill from several different start ing models but have difficulty quantitatively verifying the results. On the inverse side we are able to produce either high frequency acoustic impedance contrast sections or low frequency absolute velocity sections but not both, and without both together we cannot produce a unique solution. We need therefore substan tial improvements in both forward modelling and in version before we can unambiguously predict lithosome distribution with the chronosome. 


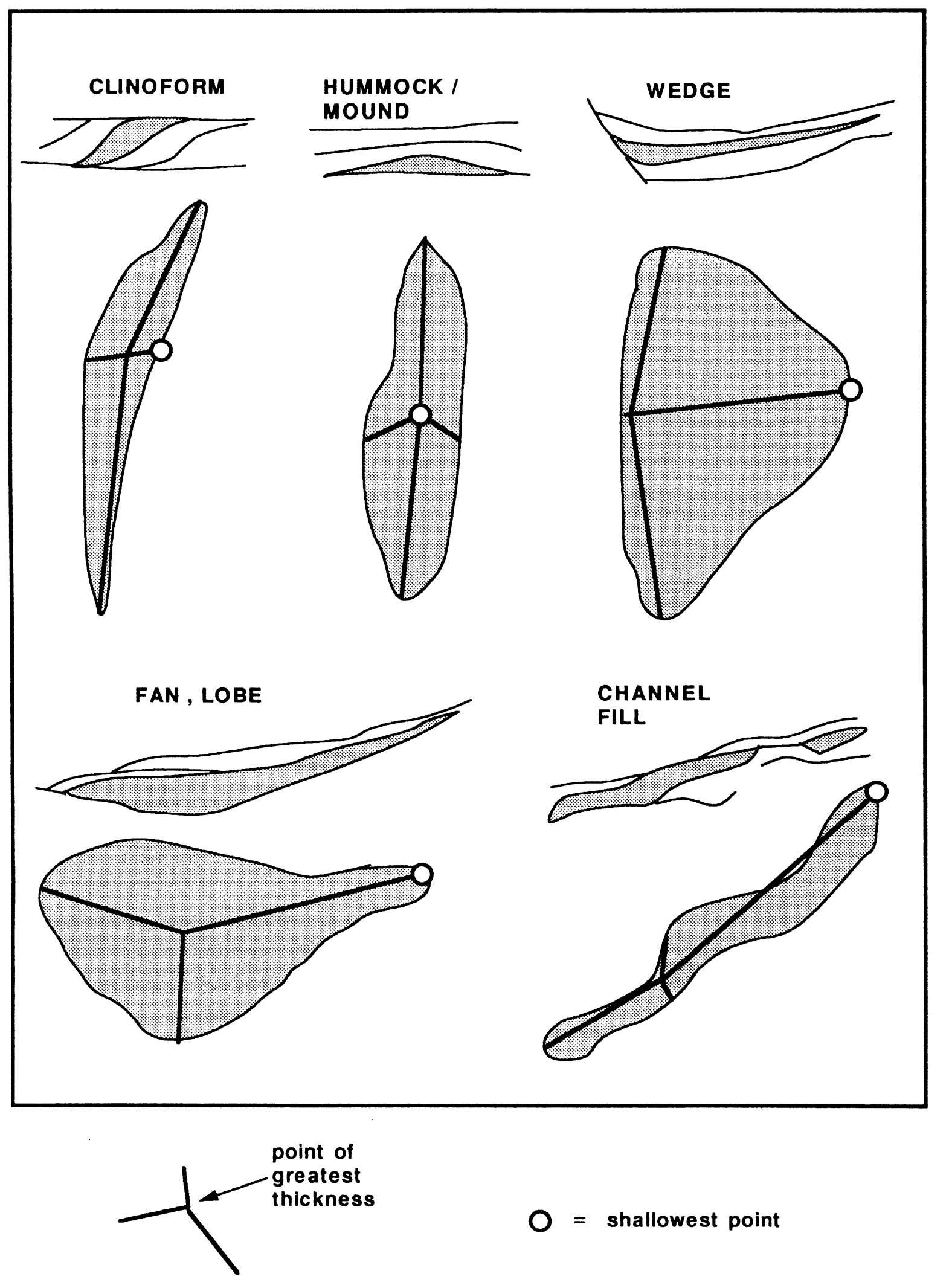

Fig.3. a. Examples of a skeletal shape description applied to different geological bodies. 
Chromosomes and quantitative stratigraphy

333
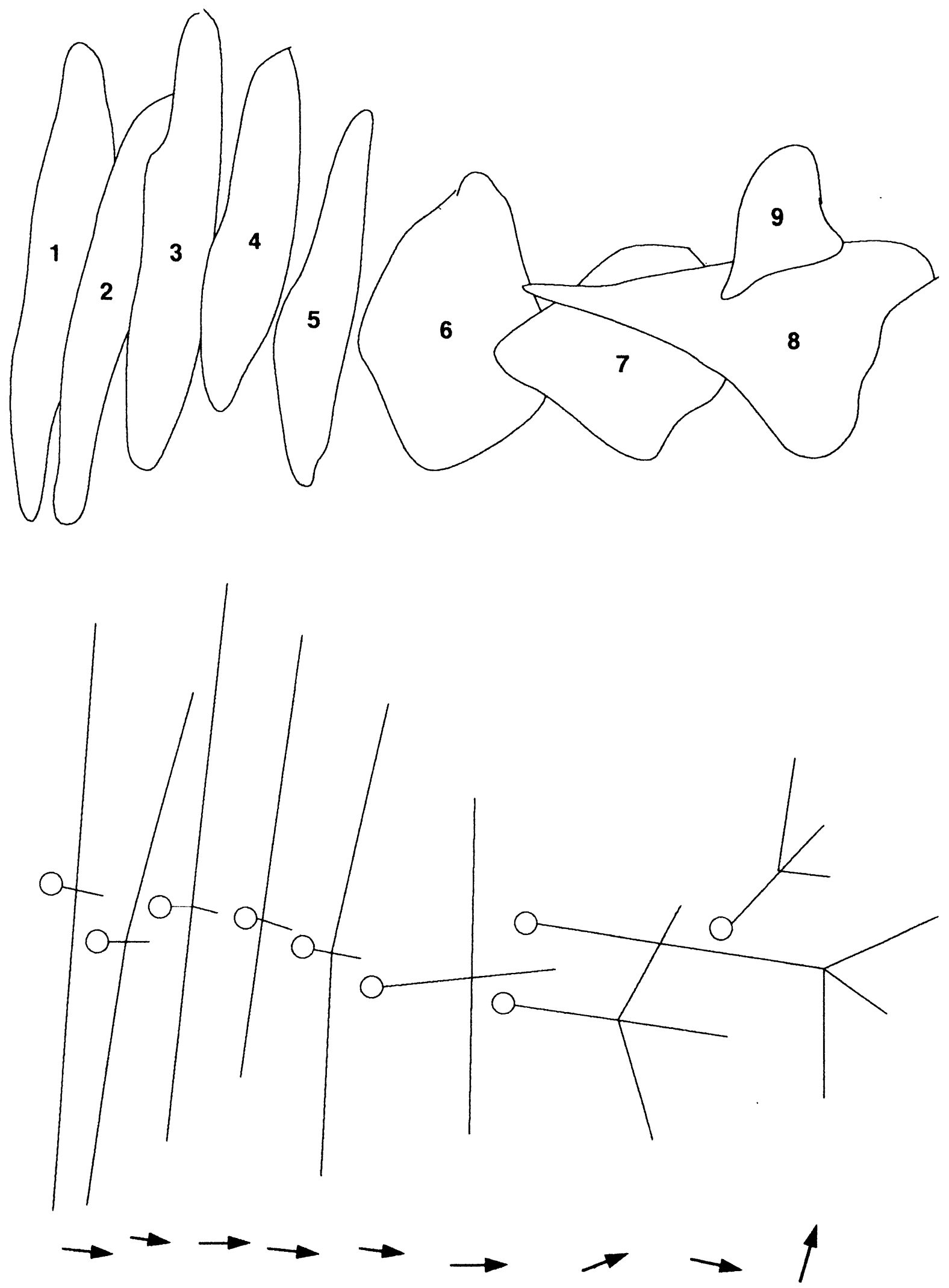

Fig.3. b. A simplified example of a series of consecutive bodies representing hallowing conditions. Nos. 1 - 5 are prograding chromosomes, 7 - 9 are delta lobes. Arrows indicate transport direction. 


\section{QUANTITATIVE BIOSTRATIGRAPHY AND THE CHRONOSOME}

Several workers have shown the dependence of paleontologic assemblages on lithology (Armentraut, (1986), McDougal (1980), Poag (1976), and Poag and Valentine (1976) etc.). This dependence may be a function of unimodal specific preference (ter Braak. 1987 , p. 1) during life, or preservation potential. Whatever the cause we should anticipate both lateral and vertical variation in paleontological assemblage within a chronosome at all scales. Quantitative map ping, and indeed prediction, of this variation in three dimensions can be assisted by the use of software such as ter Braak's CANOCO program (canonical community ordination by partial de - trended canoni cal correspondence analysis, ter Braak, 1987). Quanti fying the lithostratigraphic control on biostratigraphy in three dimensions is necessary in order help tie down the duration of the chronosome, as different ver tical sections within the chronosome will yield differ ent assemblages. the use of a probabilistic "scaled optimum sequence" (Agterterg (1990), p. 250) may help to identify those species which are potentially lithologically influenced.

\section{STRATIGRAPHIC LAWS AND THE CHRONOSOME}

Although we live in a three-dimensional world, most of our stratigraphic concepts are at most twodimensional. The law of superposition relates a verti cal sequence to relative age (in an undisturbed se quence the younger formation is spatially superim posed on the older). Although this concept is valid at each individual point throughout a basin it does not help in relating neighboring sequences, hence the need for the concept of stratigraphic correlation (the identification of coeval parts of a sequence). The Law of Superposition is thus a one-dimensional law which says nothing about three-dimensional relative time. Walther's Law concerns two-dimensional relationships (the lateral sequence of lithologies is the same as the vertical sequence in an undisturbed succes sion). In sedimentary sequences this law is true only for limited distances in the direction of deposition, and only for certain environments. The definition of " lateral" is also incomplete, do we mean along the paleoslope. or do we mean parallel to the geoid or spheroid ("horizontal"). The three-dimensional world is more complex, with many different environ ments interacting at all scales. Sediments are trans ported and deposited as a function of the local varia tions in physical or chemical gradients. Only a few meters away from a channel sand is an embayment, whereas the channel sand is overlain by a coal deposit. For Walther's law to be of use in this case we need three-dimensional information concerning the distribution of gradients and fluid energy.

The chronosome and sequence stratigraphy

Sequence stratigraphy (Vail et al. (1977), van
Wagoner (1988)) depends absolutely on the mapping. of chronosome relationships. Current published practice uses the type of termination to determine the rela tionship. Groups of related chronosomes are assigned to "system tracts" and these system tracts are quali tatively associated with lithosome prediction. The scale independence has been neatly illustrated by Posamentier et al. (1992) by studying a number of se quences developed in a road - side ditch.

Quantifying lithosome prediction within the vari ous system tracts is not possible without information concerning the three - dimensional chronosome shape, orientation and underlying surface.

\section{CONCLUSION}

A lot of effort is being currently expended throughout the world in the field of lithosome predic tion. Most of this effort is being directed towards porosity and permeability prediction in aquifers and hydrocarbon reservoirs. The field of three-dimen sional visualization has also expanded dramatically as a function of access to computing power and color graphics technology, and there seems to be some confusion in the role of such representation in lithosome prediction. The three-dimensional representation of geological bodies can only be of quantitative use in lithosome prediction if we can achieve a) a strati graphic framework for the body, b) a functional shape description, and c) a quantitative relationship between preserved shape, depositional surface, and depositional process.

A formalized three-dimensional chronosome concept is the first step towards this goal. The chronosome surface is the diachronous stratigraphic correlation surface at all scales, and is the nearest we can approach to a paleotopography. The time duration of a chronosome will vary according to the resolution of the observational technique, but at the limit of resolution the chronosome will always provide the optimum predictive unit. Any technique that im proves the resolution will also improve the predictive potential. To put this another way, one should adjust the expected resolution of prediction to the expected time duration (temporal resolution) of the chronosome. Thus, given a $1 \mathrm{Ma}$ temporal resolution in the Mesozoic. one should not expect to model sand distri bution to the same accuracy as in a $10 \mathrm{ka}$ Tertiary chronosome even though the thickness may be the same. The same process model or statistical model may be applied in both cases but the uncertainty in creases with chronosome duration. This principle may be stated in the following way:

The probability of successful prediction of lithologic properties throughout a chronosome is generally inversely proportional to its duration

The physical thickness of a chronosome is of less importance, thick sands can be deposited by a single process in very short periods of time.

We must ask the following questions of our three dimensional mapping systems therefore if we are to 
have any success in lithosome prediction. The ques tions are;

- What is the 3D form of the chronosome?

-What is its sequence stratigraphic position?

-What is its duration?

- What is its orientation and attitude?

- What is the nature of its underlying surface?

-What is its spatial relationship to neighboring chronosomes?

Once we have quantitative answers to these ques tions we can begin to choose an appropriate statistical or process model to predict lithosome distribution within the chronosome. Our expectation of success can be estimated in advance by considering the dura tion of the chronosome involved.

We can conclude that any lithosome prediction model that does not take the chronosome into consid eration has very little chance of success.

\section{ACKNOWLEDGEMENTS}

The authors are grateful for the financial support for this study provided by British Petroleum.

\section{REFERENCES}

Agterberg, F. P. (1990) Automated Stratigraphic Correlation. Elsevier, Amsterdam, 424 pp.

Agterberg, F. P., and Griffiths, C. M. (1991) Com puter applications in stratigraphy 1989/1990: A review. Computers and Geosciences, vol. 17, no. 8, pp. $1105-1118$.

Armentrout, J. M. (1986) Integration of biostratigra phy and seismic stratigraphy: Pliocene - Pleis tocene, Gulf of Mexico. Gulf Coast Section Society of Economic Paleontologists and Mineralogists Foundation, Houston, TX., December 6-9, pp. 6 14.

Auerbach, S. and Schaeben, H. (1990) Computer aided geometric design of geologic surfaces and bodies. Journal of Mathematical Geology, vol. 22, no. 8, pp. 957 - 987.

Begg, S. H., and King, P. (1985) Modeling the effects of shales on reservoir performance: Calculation of effective vertical permeability. paper SPE 13529 presented at the 1985 SPE Annual Technical Con ference and Exhibition, Las Vegas, USA 1985.

Blagdy, J - P. D. (1992) Integrated seismic lithologic interpretation: The petrophysical basis. Stanford Rock Physics \& Borehole Project., 51 pp.

Bridge, J. S., and Leeder, M. R. (1979) A simulation model of alluvial stratigraphy. Sedimentology, vol. 26, pp. $617-644$.

Chorley, R. J., Malm, D. E. G., and Pogorzelski, H. A. (1957) A new standard for estimating drainage basin shape. Amer. Jour. Sci., vol. 255, pp. 138 141.

Chorley, R. L., and Morley, L. S. D. (1959) A simplified approximation for the hypsometric integral. Jour. Geol., vol. 67, pp. 566 - 571.

Clemens, S., Prell, W., Murray, D., Shimmield, G., and Weedon, G. (1991) Forcing mechanisms of the Indian Ocean monsoon. Nature, vol. 353, 634624 Oct. 1991 , pp. $720-725$.

Connel, L. H., and Brady M. (1985) Generating and generalizing models of visual objects. A. I. Memo no. 823, AI LAB, M.I.T..

Cross, T. A. ed. (1990) Quantitative Dynamic Stratig raphy., Prentice Hall. New Jersey.

Damsleth, E., Tjølsen, C. B., Omre, H., and Hal dorsen, H. H. (1992) A Two-Stage Stochastic Model Applied to a North Sea Reservoir.. Jour. Petrol. Tech., vol. 44, no. 4, pp. 402 - 408.

Grabau, A. W. (1913) Principles of stratigraphy. Seil er, New York, 1185 pp.

Gradstein, F. M., Agterberg, F. P., and D'Iorio, M. A. (1990) Time in quantitative stratigraphy. In Cross T. A.(ed.) Quantitative Dynamic Stratig raphy, Prentice Hall, New Jersey.

Gradstein, F. M., Agterberg, F. P.. Brower, J. C., and Schwarzacher, W. S. (1985) Quantitative Stratigraphy.. D. Reidel Publishing Co./ Unesco, pp. 598.

Griffiths, C. M., Bфe, R., and Hodkinson, R. A. (1992) Frequency and sequency analysis of petro physical log data and inductively coupled argon plasma analysis of sediments in the Lau basin. in: Parson, L. Hawkins, J., Allan, J. et al. eds., Proc. ODP Scientific Results, vol. 135.

Haldorsen, H. H., and Damsleth, E. (1990) Stochastic Modelling, Jour. Petr. Technol., April, pp. 404 412.

Haldorsen, H. H., and Macdonald, C. J. (1987) Stochastic modeling of underground reservoir fa cies. Paper SPE 16751 presented at the 1987 SPE Annual technical conference, Dallas, Texas, USA, Sept. 27 - 30, 1987.

Haq, B. U., Hardenbol, J., and Vail, P. R. (1987) Chronology of fluctuating sea levels since the Tri assic. Science, vol. 235, pp. 1156 - 1167.

Harbaugh, J. W., and Bonham - Carter, G. (1970) Computer simulation in geology. New York, John Wiley and Sons, $575 \mathrm{pp}$.

Harland, W., Armstrong, R. L., Cox, A. V., Craig, L. E., Smith, A. G., and Smith, D. G. (1989) A geologic time scale. Cambridge University Press, Cambridge, UK, $263 \mathrm{pp}$.

Hewett, T. A. (1986) Fractal distribution of reservoir heterogeneity and their influence on fluid trans port. SPE I5386. Presented at 61st Annual Techni cal Conference and Exhibition of SPE, New Or leans, LA., October 5-8, 13 pp., 18 figs.

Hewett, T. A., and Behrens, R. A. (1990) Conditional simulation of reservoir heterogeneity with fractals. SPE Formation Evaluation, September 1990, pp. $217-225$.

Imbrie, J. (1985) A Theoretical framework for the Pleistocene ice ages. Jour. Geol. Soc. Lond., vol. 142 , pp. $417-432$.

Imbrie, J., and Imbrie, J. Z. (1980) Modeling the cli matic response to orbital variations. Science, vol. 207, pp. 943 - 953. 
Jacod, J., and Joathon, P. (1972) Conditional simula tion of sedimentary cycles in three dimension: in: Merriam D. F. ed. Mathematical models of sedi mentary processes, Plenum Press, New York, pp. 139 - 165. .

Jacod, J., and Joathon, P. (1971) Use of random - ge netic models in the study of sedimentary process es. Jour. Math. Geology., vol. 3, no. 3, pp. 265 279.

Johnson, N. M., Sheikh, K. A., Dawson-Saunders, E., Mcrae, L. E. Klein, H., Pflug, R., and Ramshorn, C. (1989) Shaded perspective views by computer: A new tool for geologists. Geobyte, vol. 4 , no. 4 , pp. $16-24$.

Mackey, S. D., and Bridge, J. S. (1992) A revised FORTRAN program to simulate alluvial stratig raphy., Computers \& Geosciences, vol. 18, nos. 2/ 3 , pp. $119-182$.

Markov, A. A. (1924) Probability Calculus. 4th Edi tion. Moscow State Publishing House, pp. 552 581.

Marschallinger, R. (1991) Interface programs to en able full 3 -D geological modeling with a combi nation of AutoCAD and SURFER., Computers \& Geosciences, vol. 17, no. 10, pp. 1383 - 1394.

Matheron, G. (1963) Principles of geostatistics. Reprinted from Econ. Geol., in the statistical Analysis in Geology. ed., by J. M. Cubitt \& S. Henley, vol. 58, pp. 1246 - 1266.

Matheron, G. (1962) Traite de geostatistique appliquee. Tomme 1. Paris: Editions Techniq., 333 pp.

Matheron, G. (1963) Traite de geostatistique appliquee. Tomme 2. Paris: Editions Techniq., 172 pp.

Matheron, G. (1965) Les variables regionalisees et leur estimation. Paris: Edition Masson. $166 \mathrm{pp}$.

Matheron, G. (1971) The theory of regionalised vari ables and its applications.. Fasc. S. Paris: L'ecole Nationale superieure des Mines de Paris. 211 pp.

McDougall, K. A. (1980) Paleoecological evaluation of late Eocene biostratigraphic zonations of the Pacific coast of North America.. Jour. Paleont., vol. 54, no. 4 (Pal. Monograph 2), 75 pp.

Miall, A.D. (1985) Architectural - element analysis: A new method of facies analysis applied to fluvial deposits. Earth - Science Reviews, vol. 22, pp. 261 308.

Poag, C. W., (1981) Ecological Atlas of benthic Foraminifera of the Gulf of Mexico. Marine Sci ence International, Woods Hole, Massachusetts. $174 \mathrm{pp}$.

Poag, C. W., and Valentine, P. C. (1976) Biostratigra phy and ecostratigraphy of the Pleistocene Basin, Texas-Louisiana continental shelf. Gulf Coast Assoc. Geol. Soc. Trans., no. 26, pp. 185 - 256.

Posamentier, H. W., Allen, G. P., and James, D. P. (1992) High - Resolution Sequence Stratigraphy The East Coulee Delta. Journal of Sedimentary Petrology.
Samec, P., Marion, D., and Nur, A. (1989) From sed iment transport to seismic stratigraphy: A syn thetic model. Stanford Rock Physics Laboratory Report, no. 20.

Schultz, E. H. (1982) The Chronosome and Supersome: terms proposed for low - rank chronostrati graphic units. Bull. Canad. Petrol. Geol., vol. 30, no. 1 , pp. 9 - 33 .

Schwarzacher, W. (1975) Sedimentation models and quantitative stratigraphy. Developments in Sedi mentology, no. 19. Amsterdam: Elsevier, 382 pp.

Schwarzacher, W. (1985) Quantitative Litho - stratig raphy. in: Gradstein, F. M., Agterberg, F. P., Brower, J. C., and Schwarzacher, W. S., Quanti tative Stratigraphy. D. Reidel Publishing Co., UNESCO, Paris, pp. 361 - 386.

ter Braak, C. J. F. (1987) Unimodal models to relate species to environment. Ph.D Thesis, Agricultur al Mathematics Group, Institute TNO for Mathe matics. Information Processing and Statistics. Wageningen. The Netherlands.

Thorn, C. E. (1988) Introduction to Theoretical Geomorphology. Unwin Hyman Ltd., London, pp. 247.

Tipper, J. C. (1977) Three-dimensional analysis of geological forms. Jour. Geology, vol. 85, no. 5, pp. $591-611$.

Vail, P. R., Mitchum, R. M. Jr., and Thompson, S. III.(1977) Seismic stratigraphy and global changes of sea level part 3. Amer. Assoc. Petr. Geol., Mem., no. 26, pp. 63 - 97.

van Wagoner, J. C., Posamentier, H. W., Mitchum, R. M. Jr., Vail, P. R., Sarg, J. F., Lout, and L. (1988) An overview of the fundamentals of se quence stratigraphy and key definitions, in: Wil gus, C. K., Hastings, B. S., Ross, C. A., Posa mentier, H. W., Van Wagoner, J. C. eds., Sea level changes; an integrated approach. Special Publication - Society of Economic Paleontologists, vol. 42 , pp. $39-45$.

Williams, D. F. (1988) Evidence for and against sea level changes from the stable isotopic record of the Cenozoic. in: Wilgus. C. K., Hastings, B. S., Ross, C. A., Posamentier, H. W., Van Wagoner. J. C. eds., Sea - level changes; an integrated approach. Special Publication - Society of Economic Paleontologists. vol. 42, pp. $31-36$ 